\title{
Деградация фотолюминесценции тонких пленок ZnTPP и ZnTPP-C 6 под действием гамма-облучения
}

\author{
(C) H.M. Романов ${ }^{1,2}$, М.A. Елистратова ${ }^{3}$, E. Lahderanta $^{2}$, И.Б. Захарова ${ }^{1}$ \\ ${ }^{1}$ Санкт-Петербургский политехнический университет Петра Великого, \\ 195251 Санкт Петербург, Россия \\ ${ }^{2}$ Lappeenranta University of Technology, \\ 53850 Лаппеенранта, Финляндия \\ ${ }^{3}$ Физико-технический институт им. А.Ф. Иоффее Российской академии наук, \\ 194021 Санкт-Петербург, Россия \\ E-mail: nikromanov.90@gmail.com, zakharova@rphf.spbstu.ru
}

(Получена 11 января 2018 г. Принята к печати 28 января 2018 г.)

\begin{abstract}
Порфирины и их комплексы с фуллереном являются перспективными материалами для реализации органических фотовольтаических структур. Однако стабильность свойств органических компонент под действием жесткого облучения практически не изучена. В работе исследовано влияние $\gamma$-облучения средними (порядка $\left.10^{4} \Gamma \mathrm{p}\right)$ и большими $\left(10^{7} \Gamma \mathrm{p}\right)$ дозами на фотолюминесценцию тонких структурно-совершенных пленок, как чистого порфирина ZnTPP, так и композитных пленок $\mathrm{ZnTPP} / \mathrm{C}_{60}$ в молярном соотношении $1.3: 1$. Показано, что под действием $\gamma$-облучения интенсивность электронного излучательного перехода (626 нм) уменьшается, причем дозовая зависимость носит пороговый характер. Пороговая доза составляет $~ 20$ кГр для пленок ZnTPP. В обоих типах образцов интенсивность электронно-колебательной части спектральной зависимости ФЛ (670-690 нм) увеличивалась при начальных дозах облучения и при дальнейшем возрастании дозы облучения уменьшается слабее, чем для чисто электронного перехода. В нанокомпозитных пленках добавление фуллерена в $\sim 2.5$ раза увеличивает пороговую дозу, после которой начинается деградация ФЛ пленок. При этом спектральные составляющие ФЛ, связанные с проявлением излучения фуллерена $\mathrm{C}_{60}$, более стабильны под действием $\gamma$-облучения.
\end{abstract}

DOI: $10.21883 /$ FTP.2018.08.46222.8816

\section{1. Введение}

Приборы на основе нанокомпозитных органических материалов обладают рядом уникальных преимуществ перед классическими полупроводниковыми структурами [1,2]. Сочетание таких органических материалов, как планарные молекулы порфиринов и объемные молекулы фуллерена $\mathrm{C}_{60}$ позволяет создавать диоды, донорноакцепторные комплексы, молекулярные и объемные гетеропереходы, которые могут применяться в органической фотонике для создания фотовольтаических ячеек и светоизлучающих структур [3-5]. Интерес к созданию устройств на основе молекул порфирина и металлопорфирина объясняется уникальным сочетанием оптических, электронных и биологических свойств в данном классе материалов. Наличие большой степени $\pi$-сопряжений связей обусловливает основные характеристики, такие как поглощение света в различных спектральных областях спектра, флуоресценция и донорные свойства [6,7]. Порфирины и фуллерены образуют молекулярные комплексы, в которых проявляется фотоиндуцированный перенос заряда [8]. Некоторые представители металлопорфиринов, например, коммерчески доступный тетрафенилпорфирин цинка ZnTPP и его модифицированный олигомер, могут быть использованы в качестве наноплатформы для изготовления различных светодиодов [9]. Наиболее технологически востребованы тонкопленочные нанокомпозитные порфирин-фуллереновые структуры, полученные методами вакуумного напыления [10]. Показано наличие существенной связи между структурными и оптическими свойствами агрегатов порфирина $[11,12]$. Можно утверждать, что порфирины и комплексы на их основе являются перспективными материалами для реализации объемного гетероперехода в нанокомпозитах. Однако стабильность свойств органических компонент при различных условиях применения (в присутствии кислорода, паров воды, УФ и жесткого облучения) представляет собой серьезную проблему, препятствующую развитию органической электроники. $\gamma$-излучение в силу своих физических особенностей имеет сильную проникающую способность, взаимодействие с веществом выражается в электронном возбуждении, электронной ионизации, рождении электронно-дырочной пары, что в органических материалах приводит к появлению возбужденных молекул, ионов, свободных радикалов и, в присутствии кислорода, к возможному образованию перекиси. При этом изменение свойств органических материалов под действием $\gamma$-облучения может вести как к ухудшению значимых для применения параметров, так и к модернизации свойств и появлению новых полезных характеристик. Так, показана возможность создания термически стабильного полимера посредством радиационной сшивки, определены пороговые дозы начала необратимых изменений и дозы полного последующего окисления фрагментированных звеньев. В ра- 
ботах $[13,14]$ Рассмотрены изменения фундаментальных физических и химических свойств полимеров, таких как величина запрещенной зоны, вследствие влияния $\gamma$-облучения [15]. Противоречивые, но важные результаты были получены в работе [16], в которой изучено изменение молекулярного веса полимера вследствие $\gamma$-облучения, из-за сшивания (удлинения) и разделения (укорачивания) основной полимерной цепи в зависимости от дозы облучения. Оба процесса происходят одновременно, но с разной вероятностью, что усложняет количественную оценку и прогнозирование конечных свойств материала.

Влияние $\gamma$-облучения на тонкие органические пленки представляет интерес как с точки зрения фундаментальной, так и прикладной науки. При этом в настоящее время вопрос действия облучения на порфириновые пленки изучен явно недостаточно [17], а исследования такого воздействия на нанокомпозиты не проводилось вообще. Наличие $\pi$-электронов уменьшает вероятность локализации энергии на определенной связи и способствует делокализации энергии по всему пиррольному кольцу. Ароматическое кольцо в порфиринах может обеспечить не только высокую температурную стабильность, но и радиационную стойкость материала, как отмечено в [18]. Влияние другого вида радиационного воздействия - рентгеновского излучения на тонкие порфириновые пленки представлено только косвенно [19]. Несколько большее число работ было посвящено исследованию изменения свойств фуллеренов под действием $\gamma$-облучения.

В работе [20] рассмотрены процессы олигомеризации фуллеренов $\mathrm{C}_{60}$ и $\mathrm{C}_{70}$ под влиянием совокупности поражающих факторов, а в [21] рассмотрены процессы радиолиза фуллерена. При этом показана возможность присоединения к фуллерену бензильных групп, а также окисления под действием облучения в присутствии кислорода.

Интересна также возможность ковалентной функционализации поверхности углеродных нанотрубок под действием облучения [22], что дает возможность создания новых материалов с заданными свойствами. В то же время в ряде работ отмечается стабильность свойств фуллеренов под действием $\gamma$-облучения [23], а также имеются данные, что добавление $\mathrm{C}_{60}$ ведет к улучшению радиационной стабильности свойств как органических композитов $[24,25]$, так и органо-неорганических композитов с добавкой $\mathrm{C}_{60}[26]$.

Изучено действие $\gamma$-облучения на некоторые приборные структуры, например, в работе [25] рассматриваются органические фотовольтаические элементы на основе производных фуллерена PCBM ([6.6]-phenyl- $\mathrm{C}_{61}$-butyric acid methyl ester $-\mathrm{C}_{72} \mathrm{H}_{14} \mathrm{O}_{2}$ ) для применения в космическом пространстве, что означает воздействие различных уровней излучения. Авторы исследовали деградацию вольт-амперных характеристик устройств в зависимости от различных доз $\gamma$-облучения. В работе выдвинуто предположение, что основные механизмы деградации структур связаны с сокращением длины $\pi$-сопряжения в РСВМ.

Таким образом, значительные и разнообразные по физической природе возможные изменения свойств как компонент, так и нанокомпозитов порфирин-фуллерена под действием $\gamma$-облучения требуют дальнейшего исследования. Настоящая работа направлена на изучение индуцированных $\gamma$-облучением изменений в фотолюминесценции тонких пленок ZnTPP и нанокомпозитных структур ZnTPP-C 60 .

\section{2. Методы получения и исследования образцов}

Тонкие пленки тетрафенилпорфирина цинка ZnTPP $\mathrm{C}_{44} \mathrm{H}_{28} \mathrm{~N}_{4} \mathrm{Zn} \quad(5,10,15,20$-Tetraphenyl-21H, 23H-porphine zinc) и композита ZnTPP/C 60 были получены термическим испарением в вакууме квазиравновесным методом горячей стенки. Конденсация из газодинамического потока пара при низких значениях пересыщения и достаточно высоких температурах роста позволяет формировать упорядоченные структуры органического комплекса [4]. Для получения пленок использовалась шихта, представляющая собой как промышленно доступный мелкокристаллический порошок ZnTPP (Sigma-Aldrich 99\% low chlorin) в случае однокомпонентных пленок, так и смесь ZnTPP (Sigma-Aldrich 99\% low chlorin) и $\mathrm{C}_{60}$ (Sigma-Aldrich 99.5\%) в молярном соотношении $1: 1$. В качестве подложки использовался кремний с ориентацией (111). Режимы получения пленок приведены в [12] Для изучения морфологии поверхности использовался растровый электронный микроскоп JEOL JSM-6390, элементный состав пленок изучался с помощью энергодисперсионной приставки микроанализа Oxford INCA Energy. Спектры люминесценции измерялись при комнатной температуре в непрерывном режиме с помощью автоматизированной установки на базе монохроматора Horiba Jobin Yvon FHR 640 c дифракционной решеткой 1200 шт/мм и детектора Symphony II $1024 \times 256$ Cryogenic Open-Electrode CCD. Возбуждение ФЛ производилось на длине волны 408 нм непрерывным полупроводниковым лазером мощностью 50 мВт, $\gamma$-облучение происходило на воздухе в закрытом источнике с радионуклидом $\mathrm{Cs}^{137}$, с энергией $\gamma$-квантов 661 кэВ. Образцы разделялись на две группы, по суммарной поглощенной дозе: первая группа исследовалось после получения последовательных суммарных поглощенных доз I - 17, II - 30.5, III - 55, IV - 79.5 кГр соответственно. Выбор диапазона доз позволяет сравнить результаты с большинством экспериментальных работ, где исследовались образцы, облученные дозами от $10^{3}$ до $10^{5}$ Гр. Вторая группа наших образцов была подвержена $\gamma$-облучению с большой дозой $1.6 \cdot 10^{7}$ Гр единовременно, данных по органическим материалам, облученным такими дозами, в литературе не обнаружено. 

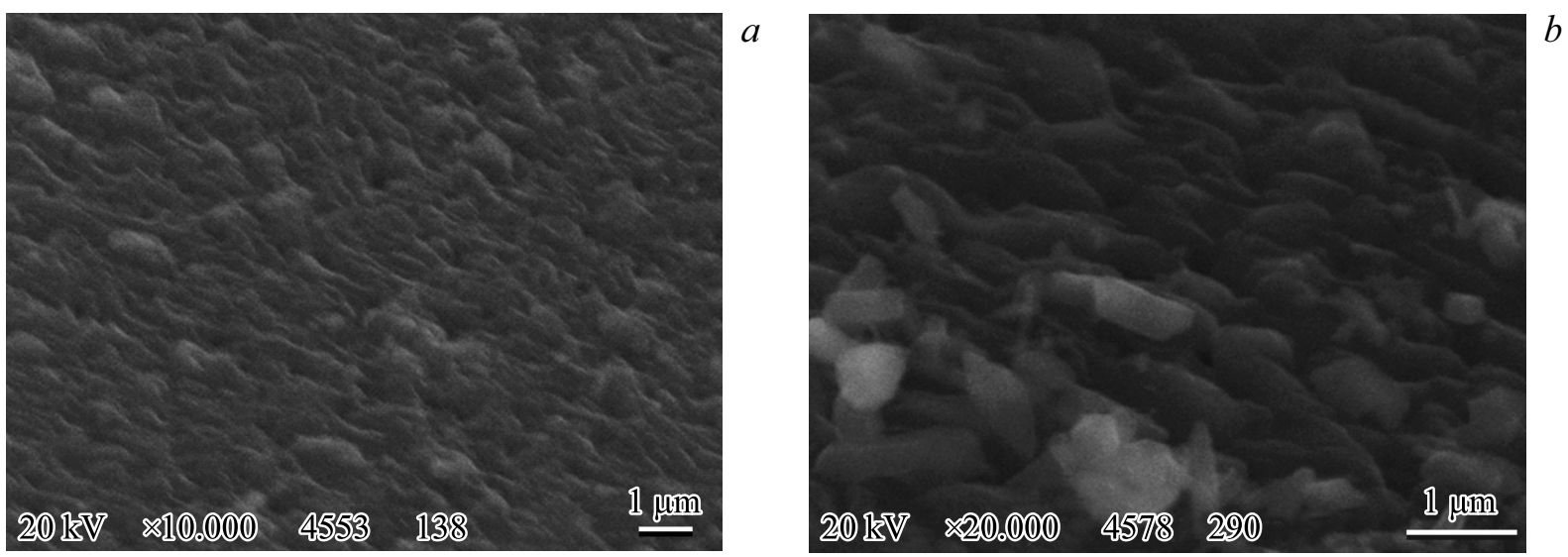

Рис. 1. Морфология поверхности пленок $\mathrm{ZnTPP}(a)$ и $\mathrm{ZnTPP} / \mathrm{C}_{60}(b)$.

\section{3. Экспериментальные результаты и обсуждение}

Результаты исследования морфологии поверхности и состава порфиринового и композитного образцов приведены на рис. $1, a, b$ и в таблице. Полученная в квазиравновесных условиях пленка ZnTPP имеет поликристаллический характер с хорошо ограненными кристаллитами, в основном стержневидной формы, шириной около 300 нм и длиной до 1 мкм. Следует отметить значительное различие структуры образцов от пленок, полученных стандартным методом напыления из молекулярного пучка, которые [10] имели аморфную структуру.

Поверхности композитных пленок имеют более развитый характер из-за наличия, кроме однородной крупнокристаллической фазы композитной пленки, незначительных включений ZnTPP в виде наностержней, растущих под углом к поверхности пленки. В такие структуры самоорганизуются порфириновые молекулы в условиях, близких к равновесным на углеродной подложке [27]. При изучении состава тонких пленок и использовании ускоряющих напряжений 10-20 кэВ регистрируемый элементный состав искажался присутствием дополнительного сигнала характеристического рентгеновского излучения от $\mathrm{Si}$-подложки. Поэтому для

Расчетные и экспериментально полученные данные по составу пленок ZnTPP и композитных пленок $\mathrm{ZnTPP} / \mathrm{C}_{60}$

\begin{tabular}{c|c|c|c|c}
\hline \multirow{2}{*}{ Элемент } & \multicolumn{4}{|c}{ Bec \% } \\
\cline { 2 - 5 } & \multicolumn{2}{|c|}{$Z n T P P$} & \multicolumn{2}{c}{$Z n T P / C_{60}$} \\
\cline { 2 - 5 } & по закладке & эксперимент & по закладке & эксперимент \\
\hline $\mathrm{Zn}$ & 9.62 & 9.56 & 4.81 & 5.90 \\
$\mathrm{C}$ & 77.72 & 81.57 & 88.86 & 86.53 \\
$\mathrm{H}$ & 4.42 & - & 2.21 & - \\
$\mathrm{N}$ & 8.24 & 8.15 & 4.12 & 6.17 \\
$\mathrm{O}$ & - & 0.65 & - & 1.40
\end{tabular}

интерпретации экспериментальных данных полученные результаты, относящиеся к весовому составу, нормализовались на 100\%, затем производилась их перенормировка, исключающая весовой вклад $\mathrm{Si}$-подложки. Отметим, что данный метод не позволяет детектировать водород, присутствующий в органическом материале, и его весовой вклад в конечный результат; тем самым в измерение неизбежно вносится систематическая приборная погрешность.

В таблице представлены данные о составе экспериментально полученных тонких пленок в сравнении с исходной шихтой. Наблюдаемое незначительное присутствие кислорода может быть связано с адсорбированным кислородом и парами $\mathrm{H}_{2} \mathrm{O}$ и не свидетельствует об окислении пленки. Компонентный состав пленок, представленный в таблице, показывает, что для пленки чистого ZnTPP полученные экспериментальные значения содержания элементов близки к стехиометрическим значениям содержания элементов в комплексе. Для пленки нанокомпозита $\mathrm{ZnTPP} / \mathrm{C}_{60}$ наблюдается некоторое расхождение с расчетными значениями состава исходной шихты в сторону уменьшения содержания фуллерена. Данный факт объясняется тем, что при температуре испарения давление насыщенных паров порфирина выше, чем фуллерена, что при испарении из смеси компонент приводит к обеднению конденсата фуллереном и относительному увеличению содержания порфирина по сравнению с исходной шихтой. Экспериментальные данные показывают, что содержание ZnTPP в пленках по сравнению с расчетным в шихте увеличено в 1.3 раза. Таким образом, в композитной пленке наряду с молекулярным комплексом $\mathrm{ZnTPP} / \mathrm{C}_{60}$ присутствует избыточный тетрафенилпорфирин цинка в виде включений (наностержней на поверхности пленки), либо в виде комплексов состава $\mathrm{C}_{60} /(\mathrm{ZnTPP})_{2}$. Подробно данные о составе и структуре различных порфириновых и фуллерен-порфириновых композитных пленках, полученных данным методом, приведены в [27]. 


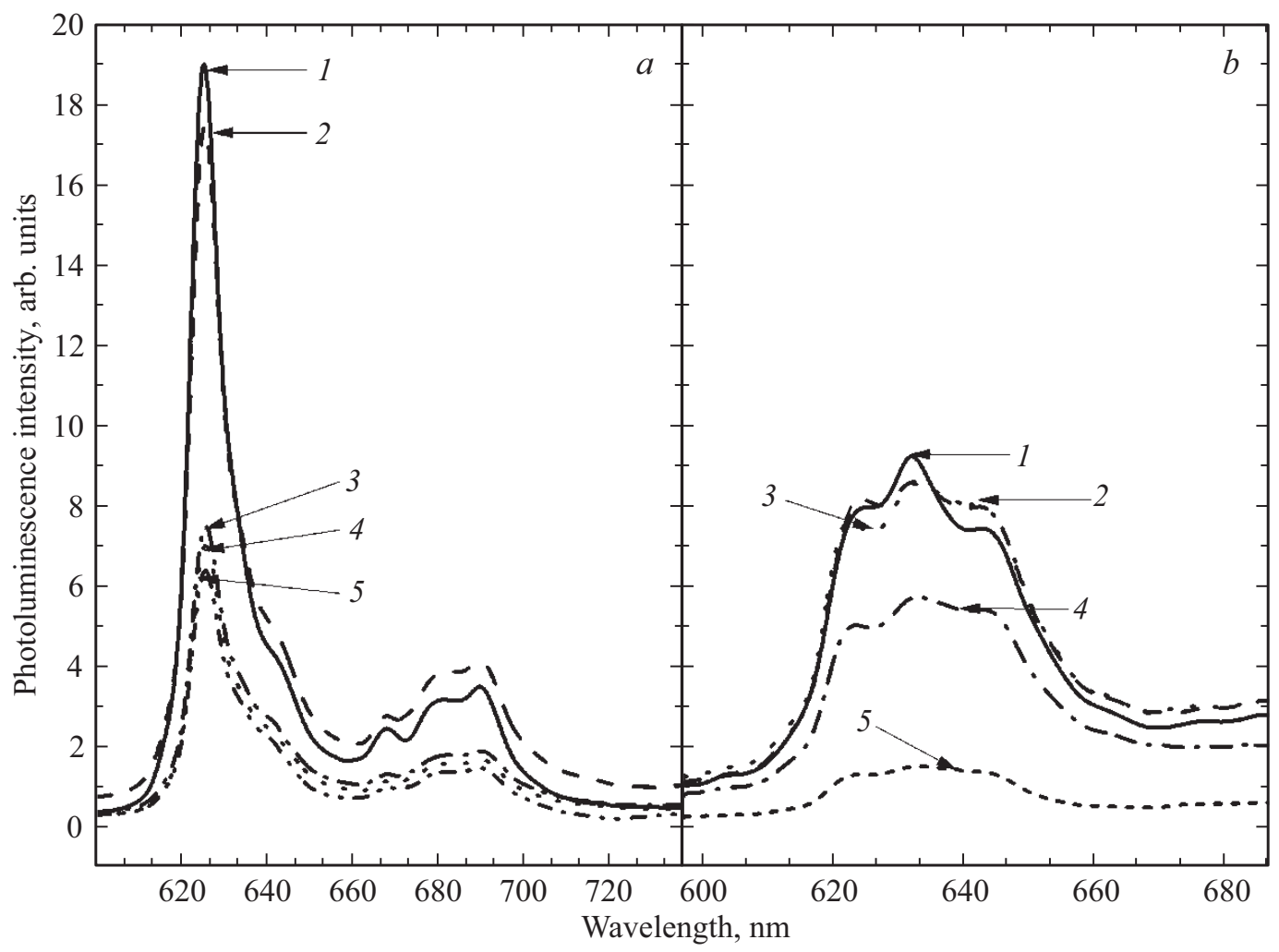

Рис. 2. Спектральная зависимость фотолюминесценции ZnTPP $(a)$ и нанокомпозита ZnTPP/C 60 (b): 1 - до воздействия ионизирующего излучения, 2 - после воздействия дозой 17 кГр, 3 - после воздействия дозой 30.5 кГр, $4-$ после воздействия дозой 55 кГр, 5 - после воздействия дозой 79.5 кГр.

\section{1. Фотолюминесценция}

На рис. 2, $a, b$ представлены спектральные зависимости фотолюминесценции первой группы пленок ZnTPP и композитных пленок $\mathrm{ZnTPP} / \mathrm{C}_{60}$, как исходных, так и после воздействия возрастающих доз $\gamma$-облучения. На исходных пленках формирование молекулярного комплекса при квазиравновесном методе получения было нами показано ранее по появлению слабой зоны дополнительного длинноволнового поглощения [28] и люминесценции при температуре $77 \mathrm{~K}$ [4], что хорошо согласуется с результатами работы по изучению поглощения в комплексах [29].

После получения пленки как чистого порфирина, так и композитные подвергались последовательному облучению с возрастающими дозами, после каждой полученной дозы облучения измерялись спектральные зависимости люминесценции. В работе [17] было показано, что при облучении дозой $1.5 \cdot 10^{5} \Gamma \mathrm{p}$ не наблюдается какихлибо изменений в колебательном спектре порфирина, что свидетельствует о хорошей стабильности самой молекулы к действию $\gamma$-облучения. Слабые изменения в оптическом спектре порфирина после $\gamma$-облучения наблюдались только вблизи края поглощения, в то время как основные линии поглощения в фиолетовой и УФ частях спектра (полоса Соре), отвечающие за электрон-электронные переходы, оставались стабильны- ми. Нашей задачей было исследовать изменения электронной структуры в $Q$-зоне, в диапазоне энергий ниже HOMO-LUMO в зависимости от дозы, поэтому как наиболее информативный был выбран метод измерения спектральной зависимости фотолюминесценции.

Исходный вид спектральной зависимости ФЛ чистого ZnTPP, как показано в [12], соответствует агрегированному (димеризованному) связанному состоянию молекул ZnTPP и смещен в длинноволновую область на 20-30нм по сравнению с спектром мономеров ZnTPP. На спектре имеется два выраженных пика. Коротковолновый на длине волны 626 нм является проявлением электронного излучательного перехода S1-S0 и имеет „Плечо“ на длине волны 636 нм, связываемое нами с наличием в пленке двух типов упорядоченных агрегированных форм. Длинноволновая полоса отвечает электронно-колебательному (вибронному) повторению основного перехода. При образовании комплекса $\mathrm{ZnTPP} / \mathrm{C}_{60}$ происходит существенное усложнение спектра излучения, которое мы рассмотрим подробнее.

Во-первых, проявляется тушение ФЛ порфирина, связанное с фотоиндуцированным переносом заряда на фуллерен, являющийся сильным акцептором. При этом отмечается некоторое относительное увеличение ФЛ в области 700-800 нм. В этой области расположена как слабая полоса фосфоресценции $\mathrm{C}_{60}(750-800$ нм$)$ [30], так и слабый пик фосфоресценции ZnTPP (745 нм), 


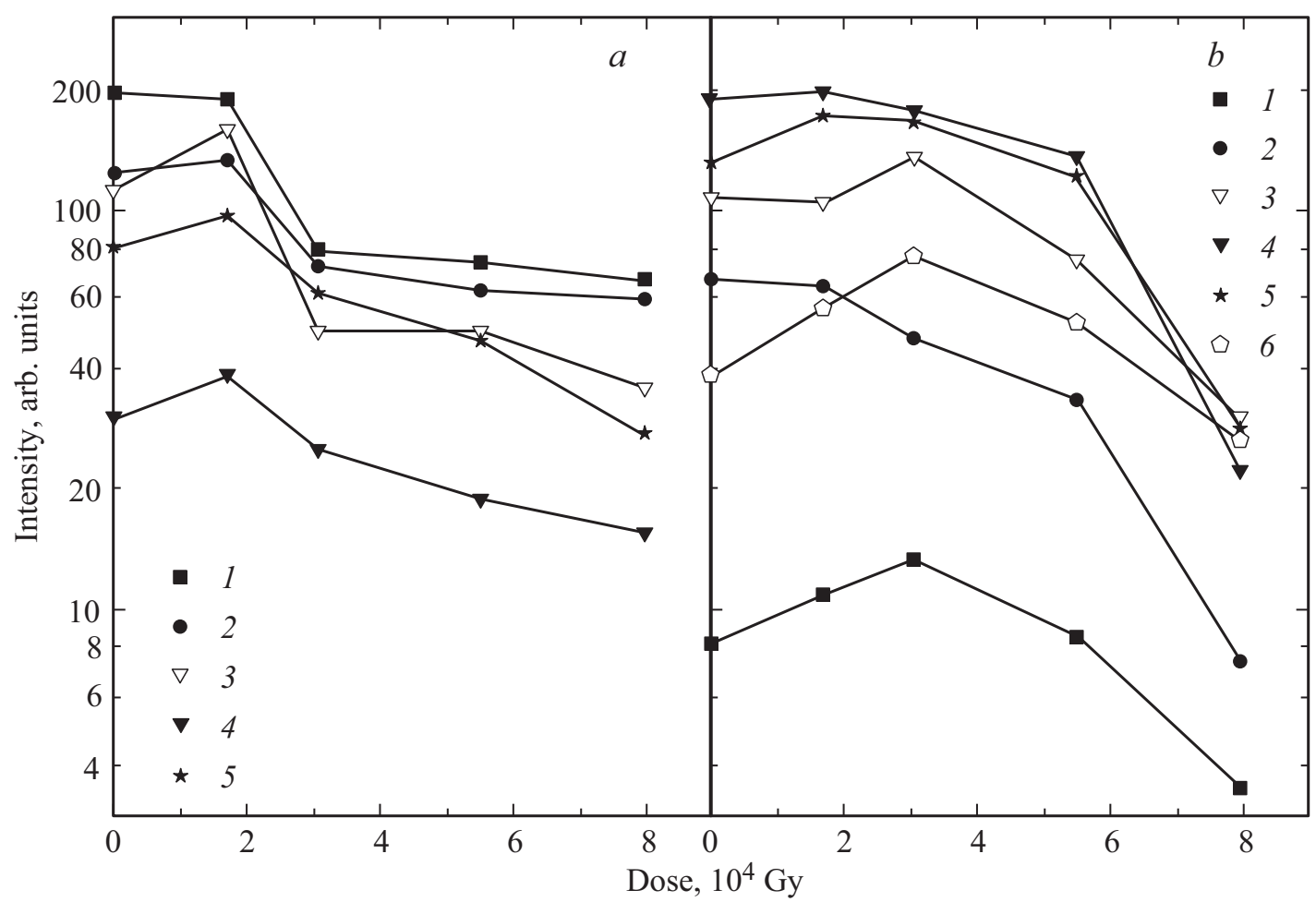

Рис. 3. Зависимость интенсивности ФЛ для различных спектральных составляющих ФЛ пленок от дозы $\gamma$-облучения: $a-$ пленка ZnTPP, где $1-626,2-636,3-677,4-690,5-745$ нм; $b-$ пленка ZnTPP/C 60 , где $1-591,2-622,3-632,4-640$, $5-685,6-755$ нм.

соответствующие переходам $\mathrm{T} 1-\mathrm{S} 0$ в соответствующих молекулах. Поэтому возможно как некоторое увеличение фосфоресценции тетрафенилпорфирина цинка, связанное со снятием интеркомбинационного запрета, так и увеличение $Ф Л \mathrm{C}_{60}$, связанное с фотоиндуцированным переносом заряда. Отмечено также появление коротковолнового пика ФЛ на длине волны 590 нм. Ранее такой пик отмечался нами для композитных пленок на основе $\mathrm{C}_{60}$ [31]. Мы интерпретировали эту полосу как проявление излучения при синглет-синглетном S1-S0 переходе в $\mathrm{C}_{60}$, симметрийный запрет на который может быть снят при формировании молекулярного комплекса. Однако в основном тушение ФЛ при взаимодействии с фуллереном обусловлено увеличением безызлучательной рекомбинации.

Во-вторых, образование комплекса приводит к расщеплению основного пика электронного излучательного перехода (626 нм) на две линии - 622 и 632 нм, при этом относительной вклад ранее существовавшей линии 640 нм увеличивается, что в целом приводит к уширению полосы. Следует отметить, что в композитных образцах, получаемых в разных режимах и имеющих соответственно несколько различающееся молярное соотношение компонент, всегда проявляются все три линии излучения, однако их относительная интенсивность может меняться. Мы связываем это расщепление с искажением симметрии ZnTPP при взаимодействии с фуллереном, однако не исключаем и возможное наличие двух разных типов молекулярного комплекса $\mathrm{ZnTPP} / \mathrm{C}_{60}$.

B-третьих, положение электронно-колебательной (вибронной) полосы в спектре существенно не изменяется, что свидетельствует о слабом влиянии взаимодействия с фуллереном на колебательный спектр жесткого порфиринового каркаса.

Рассмотрим изменения, проявляющиеся в спектральных зависимостях под действием возрастающих доз $\gamma$-облучения. На рис. 3 видно, что облучение возрастающими дозами в диапазоне от 17 до 80 кГр в целом приводит к уменьшению интенсивности ФЛ, однако эти изменения немонотонны и различны для разных полос спектра как ZnTPP, так и композита. Для детального изучения воздействия излучения на спектральные зависимости было проведено математическое разложение спектров на набор спектральных линий и построены дозовые зависимости интенсивности спектральных составляющих для порфиринового и композитного образцов (рис. 3, $a$ и $b$ ). Для образца ZnTPP интенсивность излучения линии основного электронного перехода $Q$-зоны (1) уменьшается с ростом дозы поглощенного $\gamma$-излучения, однако это явление носит пороговый характер, падение интенсивности начинается с дозы около 20 кГр. При этом интенсивность линий 3,4 (677 и 690нм), относящихся к электронно-колебательному переходу, при начальных дозах даже несколько возрастает, и в дальнейшем их падение менее выражено. Аналогичное 


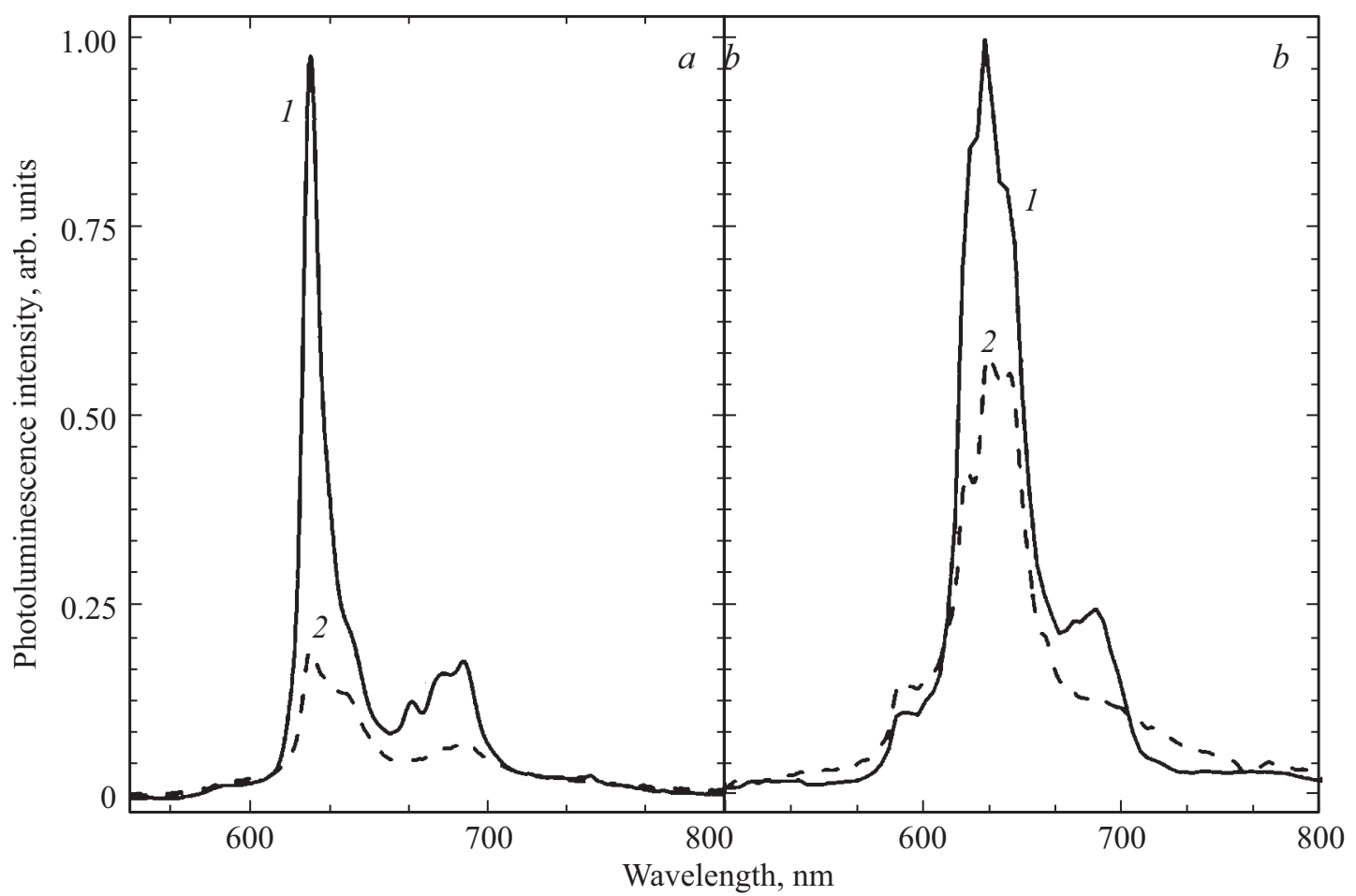

Рис. 4. Нормированные спектры фотолюминесценции ZnTPP (a) и нанокомпозита ZnTPP/C $\mathrm{Z}_{60}(b): 1$ - до воздействия ионизирующего излучения, 2 - после воздействия дозой $1.6 \cdot 10^{7}$ Гр (интенсивность $\times 5$ ).

поведение отмечено для слабой линии фосфоресценции на 745 нм. Таким образом, для пленок чистого порфирина при общем уменьшении интенсивности линий излучательных переходов растет относительный вклад электронно-колебательного излучения. Заметим, что, в отличие от твердой упорядоченной фазы, в растворах и аморфных пленках ZnTPP интенсивность излучения электронно-колебательных (вибронных) линий $Q(0,1)$ изначально больше, чем линий $Q(0,0)$, поскольку для изолированной молекулы чисто электронный переход является квазизапрещенным. Таким образом, изменения спектров ФЛ при облучении можно связать с нарушением упорядочения (разрушением димеров) в твердотельной пленке. Этот вывод согласуется с результатами работы [17], в которой при дозах, характерных для первой серии наших образцов, наблюдалось изменение структуры пленок NiTPP, а именно уменьшение среднего размера кристаллитов. Уменьшение интенсивности ФЛ может быть связано с ростом центров безызлучательной рекомбинации, связанных с дефектами в кристаллах (упорядоченной структуры). Нельзя исключить также и возможное взаимодействие с кислородом, поскольку облучение происходило на воздухе, что приводит к возникновению активного озона и возможному окислению пленок.

При сравнении дозовых зависимостей деградации ФЛ композитных пленок (рис. 3,b) видны значительные отличия. Главное отличие - пороговая доза для начала резкого падения интенсивности излучения электронного перехода существенно, в 22.5 раза, возрастает и доходит до 60 кГр. Однако после достижения порогового значения интенсивность излучения падает сильнее. Линия, связанная с электронно-колебательным переходом $(685$ нм), так же как и в чистом порфирине, увеличивает свою интенсивность при начальных дозах облучения, что также может свидетельствовать о разупорядочении образца. Линии 1 и 5 связываются нами с излучением фуллереновых молекул, линия 1 - с запрещенным по симметрии сингет-синглетным переходом, который проявляется из-за нарушения симметрии молекулы, например при полимеризации или образовании комплекса. Линия 5, вероятно, связана с проявлением фосфоресценции скорее $\mathrm{C}_{60}$, чем $\mathrm{ZnTPP}$, поскольку положение этой линии в композитных пленках более длинноволновое, чем возможная фосфоресценция порфириновых пленок, и относительная величина ее больше. При облучении интенсивность этих составляющих спектра увеличивается, линия фосфоресценции практически до конечных доз не показывает уменьшения интенсивности по сравнению с исходной пленкой. Таким образом, $\gamma$-облучение не приводит к существенной деградации $\mathrm{C}_{60}$.

Для исследования стабильности при больших дозах было проведено облучение обоих типов образцов дозой $\gamma$-облучения, увеличенной более чем на 2 порядка (рис. 4, $a, b)$. Данные о влиянии таких больших доз облучения как на порфирины, так и на фуллерены в литературе отсутствуют. Облучение дозой $1.6 \cdot 10^{7} \Gamma \mathrm{p}$ вызвало уменьшение интенсивности фотолюминесцен- 
ции пленок чистого $\mathrm{ZnTPP}$ в области электронного перехода по сравнению с исходной в $\sim 6$ раз (рис. $4, a$ ), однако ФЛ даже при таких сверхбольших дозах остается значительной и ее спектральная зависимость, положение электронного и электронно-колебательного пиков не изменяются. Аналогично для композитных пленок при падении интенсивности в 8 раз положение линий расщепленного электронного пика не изменяется. Однако относительная величина полос в области длин волн 591 и 755 нм, связываемых нами с проявлением ФЛ фуллереновой составляющей композита увеличилась. Отметим, что в композитной пленке электронколебательная полоса стала бесструктурной и превратилась фактически в „хвост“", характерный для неупорядоченных материалов. Таким образом, хотя в обоих типах образцов наблюдается падение ФЛ при сверхбольших дозах в 6-8 раз, появление пиков излучения мономеров ZnTPP (на длинах волн 600 и 650 нм), характерных для аморфных пленок, не отмечается, а структура и положение линий электронного спектра говорит о том, что сохраняющееся излучение связано с упорядоченной фазой $\mathrm{ZnTPP}$ и $\mathrm{ZnTPP} / \mathrm{C}_{60}$.

\section{4. Заключение}

В работе исследовано влияние $\gamma$-облучения средними (порядка $\left.10^{4} \Gamma \mathrm{p}\right)$ и большими $\left(10^{7} \Gamma \mathrm{p}\right)$ дозами на ФЛ тонких структурно-совершенных пленок как чистого порфирина ZnTPP, так и композитных пленок $\mathrm{ZnTPP} / \mathrm{C}_{60}$ в молярном соотношении $1.3: 1$. Показано, что добавление фуллерена $\mathrm{C}_{60}$ приводит к тушению ФЛ в области перехода $\mathrm{S} 1-\mathrm{S} 0$ и возрастанию ФЛ в более коротковолновой и более длинноволновой областях, что мы связываем с проявлением ФЛ $\mathrm{C}_{60}$. При воздействии $\gamma$-облучения выявлен пороговый характер дозовой зависимости ФЛ, причем добавление фуллерена примерно в 2 раза увеличивает пороговую дозу, после которой начинается деградация ФЛ пленок. В композитных пленках спектральные составляющие ФЛ, связанные с проявлением излучения фуллерена $\mathrm{C}_{60}$, возрастают под действием $\gamma$-облучения.

Исследование пленок, подвергнутых сверхбольшим дозам $\gamma$-облучения, показало, что эта тенденция сохраняется для больших доз до $10^{7}$ Гр. Отмеченные особенности не противоречат данным о высокой стабильности фуллерена к $\gamma$-облучению.

\section{Список литературы}

[1] M. Jurow, A.E. Schuckman, J.D. Batteas, C.M. Drain. Coord. Chem. Rev., 254 (19), 2297 (2010).

[2] A. Suzuki, K. Nishimura, T. Oku. Electronics, 3(1), 112 (2014).

[3] M.G. Walter, A.B. Rudineb, C.C. Wamser. J. Porphyrins Phthalocyanines, 14 (7), 759 (2010).

[4] М.А. Елистратова, И.Б. Захарова, Н.М. Романов, В.Ю. Паневин, О.Е. Квятковский. ФТП, 50 (9), 1213 (2016).
[5] И.Б. Захарова, В.М. Зиминов, Н.М. Романов, О.Е .Квятковский, Т.Л. Макарова. ФТП, 56 (5), 1024 (2014).

[6] H.M. Zeyada, M.M. Makhlouf, M.A. Ali. Jpn. J. Appl. Phys., 55 (2), 022601 (2016).

[7] Г.П. Гуринович, А.Н. Севченко, К. Н. Соловьев. УФН, 79, 173 (1963).

[8] S.K. Sugunan, B. Robotham, R.P. Sloan, J. Szmytkowski, K.P. Ghiggino, M.F. Paige, R.P. Steer. J. Phys. Chem. A, $115(44), 12217$ (2011).

[9] J.C. Ostrowski, K. Susumu, M.R. Robinson, M.J. Therien, G.C. Bazan. Adv. Mater., 15 (15), 1296 (2003).

[10] C. Trinh, M.T. Whited, A. Steiner, C.J. Tassone, M.F. Toney, M.E. Thompson. Chem. Mater., 24 (13), 2583 (2012).

[11] X.L. Zhang, J.W. Jiang, Y.T. Liu, S.T. Lou, C.L. Gao, Q.Y. Jin. Sci. Rept., 6, 22756 (2016).

[12] И.Б. Захарова, М.А. Елистратова, Н.М. Романов, О.Е. Квятковский. ФТП (2018).

[13] D. Sinha, T. Swu, S.P. Tripathy, R. Mishra, K.K. Dwivedi, D. Fink. Radiat, Eff. Defects Solids, 158 (7), 531 (2003).

[14] A. Mizera, M. Manas, D. Manas, M. Stanek, J. Cerny, M. Bednarik, M. Ovsik. Int. J. Math. Comput. Simulat., 6 (6), 584 (2012)

[15] M.F Zaki. J. Phys. D: Appl. Phys., 41 (5), 175404 (2008).

[16] A. Tidjani, Y. Watanabe. J. Polym. Sci. A: Polym. Chem., 33 (9), 1455 (1995).

[17] M.M. El-Nahass, H.M. Abd El-Khalek, A.M. Nawar. Optics Commun., 285 (7), 1872 (2012).

[18] D.J.Y.S. Page, H.W. Bonin, V.T. Bui, P.J. Bates. J. Appl. Polym. Sci., 86 (11), 2713 (2002).

[19] M.M. El-Nahass, A.H. Ammar, A.A. Atta, A.A.M. Farag, E.F.M. El-Zaidia. Optics Commun., 284 (9), 2259 (2011).

[20] F. Cataldo, G. Strazzulla, S. Iglesias. Mon. Not. R. Astron. Soc., 394 (2), 615 (2009).

[21] F. Cataldo, E. Lilla, O. Ursini, G. Angelini. J. Radioanal. Nucl. Chem., 279 (1), 31 (2009).

[22] S.P. Jovanovic, Z.M. Markovic, D.N. Kleut, D.D. Tosic, D.P. Kepic, M.T. Marinovic-Cincovic, B.M. TodorovicMarkovic. Hemijska Industrija, 65 (5), 479 (2011).

[23] V.A. Basiuk, G. Albarran, E.V. Basiuk, J.M. Saniger. Adv. Space Res., 36 (2), 173 (2005).

[24] F. Cataldoa, O. Ursinib, G. Angelinib. Rad. Phys. Chem., 77 (6), 742 (2008).

[25] A.M. Todd, T. Zhua, F. Zhang, C.U. Zhang, A.D. Berger, J. Xu. Chem. Mater., 16 (23), 4533 (2004).

[26] M.A. Elistratova., I.B. Zakharova, N.M. Romanov. J. Phys.: Conf. Ser., 586 (1), 012002 (2015).

[27] Н.М. Романов, И.Б. Захарова. НТВ СПбПУ, 2 (242), 9 (2016).

[28] И.Б. Захарова, О.Е. Квятковский, Е.Г. Доненко, Ю.Ф. Бирюлин. ФТТ, 51 (9), 1860 (2009).

[29] A.L. Litvinov, D.V. Konarev, A.Yu. Kovalevsky, P. Coppensband, R.N. Lyubovskaya. Cryst. Eng. Commun., 5 (25), 137 (2003).

[30] E. Cavar, M.C. Blüm, M. Pivetta, F. Patthey, M. Chergui, W.D. Schneider. Phys. Rev. Lett., 95 (19), 196102 (2005)

[31] И.Б. Захарова, В.М. Зиминов, Н.М. Романов, О.Е. Квятковский, Т.Л. Макарова. ФТТ, 56 (5), 1024 (2014).

Редактор Г.А. Оганесян 


\title{
Degradation of photoluminescence ZnTPP and $\mathrm{ZnTPP}-\mathrm{C}_{60}$ thin films under gamma irradiation
}

\section{N.M. Romanov ${ }^{1,2}$, M.A. Elistratova ${ }^{3}$, I.B. Zakharova ${ }^{1}$,} E. Lahderanta ${ }^{2}$

${ }^{1}$ Peter the Great St. Petersburg Polytechnic University, 195251 St. Petersburg, Russia

${ }^{2}$ Lappeenranta University of Technology, 53850 Lappeenranta, Finland

${ }^{3}$ loffe Institute,

194021 St. Petersburg, Russia

\begin{abstract}
Porphyrins and their fullerene complexes are promising materials for organical photovoltaic structures. However, the stability of the properties of organic structures under hard irradiation have not been studied enough. The influence of gamma irradiation with medium (about $10^{4} \mathrm{~Gy}$ ) and large $\left(10^{7} \mathrm{~Gy}\right)$ doses on the photoluminescence of thin films, both pure ZnTPP films and $\mathrm{ZnTPP} / \mathrm{C}_{60}$ composite films in a molar ratio of $1.3: 1$, was investigated. It is shown that the intensity of the electronic radiative transition $(626 \mathrm{~nm})$ decreases, and the dose dependence is threshold under the gamma irradiation. The threshold dose is approximately $20 \mathrm{kGy}$ for ZnTPP films. In both types of samples, the intensity of the electron-vibrational part of the photoluminescence spectra $(670-690 \mathrm{~nm})$ increased at initial doses of irradiation. Further increases the irradiation dose lead to decreases this transition, but less than for a purely electronic transition. In nanocomposite films, the adding of fullerene lead to approximately 2.5 times increasing the threshold degradation dose. In this case, the spectral components of PL associated with the radiation transition of $\mathrm{C}_{60}$ fullerene are more stable under the action of gamma irradiation.
\end{abstract}

